\title{
Effect of Cold Work on Creep Rupture Strength of Alloy263
}

\author{
Naoya Kanno, Yoshiki Shioda, Keiji Kubushiro \\ Materials Department, Research Laboratory, IHI Corporation, Yokohama, Japan
}

Email address:

naoya_kanno@ihi.co.jp (N. Kanno)

To cite this article:

Naoya Kanno, Yoshiki Shioda, Keiji Kubushiro. Effect of Cold Work on Creep Rupture Strength of Alloy263. International Journal of Materials Science and Applications. Vol. 6, No. 5, 2017, pp. 60-268. doi: 10.11648/j.ijmsa.20170605.16

Received: September 13, 2017; Accepted: September 22, 2017; Published: October 13, 2017

\begin{abstract}
Creep rupture strength and the microstructure change during creep deformation of pre-strained Alloy263 were investigated. Creep rupture tests were conducted at 1023, $1073 \mathrm{~K}$ at stress range from 120 to $250 \mathrm{MPa}$. Creep strength of the pre-strained samples was higher than that of the non-strained samples. However, rupture strain of the pre-strained samples was much lower than that of non-strained samples. In the pre-strained samples, $\mathrm{Ni}_{3}(\mathrm{Al}, \mathrm{Ti})-\gamma^{\prime}$ and $\mathrm{M}_{23} \mathrm{C}_{6}$ inside of the grains precipitated finer than the non-strained samples compared at the same creep time. At grain boundaries, the grain boundary shielding ratio covered by $\mathrm{M}_{23} \mathrm{C}_{6}$ carbide showed almost same value among each samples. However, diameter of the $\mathrm{M}_{23} \mathrm{C}_{6}$ particle decreased in pre-strained samples. Furthermore, dynamic recrystallization was promoted and precipitation free zone (PFZ) was formed around $\mathrm{Ni}_{3} \mathrm{Ti}-\eta$ phase at grain boundary. These observations show that increase in creep-strength of pre-strained sample was due to increase in precipitation strengthening in the grain by fine precipitation of $\gamma^{\prime}$ and $\mathrm{M}_{23} \mathrm{C}_{6}$. In addition, resistance against crack propagation at grain boundary increased by the fine precipitation of grain boundary $\mathrm{M}_{23} \mathrm{C}_{6}$ even though formation of PFZ and promotion of the dynamic recrystallization. It is estimated that Orowan-stress of pre-strained samples was 1.7 times higher than non-strained samples. It is considered that these strengthening effects overcome the weakening effects in the pre-strained samples.
\end{abstract}

Keywords: A-USC, Alloy263, Cold-Work, Creep Strength, Microstructure, Precipitation Strengthening, Carbides, $\gamma$ '

\section{Introduction}

Currently, higher thermal efficiency in the fossil power plants is required with a view to cover increasing power demand and to reduce an amount of greenhouse effect gas emission [1]. In order to improve thermal efficiency in a fossil power plant, $973 \mathrm{~K}$ class Advanced Ultra Super Critical (A-USC) power plant has been developed, whose steam temperature and pressure of the boiler have increased from $873 \mathrm{~K}$ class USC power plant [2 4]. The thermal efficiency of power generation will be expected to improve in A-USC power plant. For the boiler tube material of A-USC power plant, excellent creep rupture strength and good corrosion resistant properties are required compared to the existing ferritic heat resistant steels. Several Ni-based alloys have been investigated as hopeful candidate materials for A-USC boiler tube. Especially, Alloy263 shows superior high temperature mechanical property $[5,6]$.

Normally, plastic strain has been applied to boiler tube materials by cold work during the fabrication process. It is important to investigate the effect of plastic strain by cold work on creep rupture strength for reasons of carrying out the heat treatment after fabrication process and the long term creep life prediction of boiler tube material. Several works researched the effect of plastic strain on high temperature strength in Ni-based alloys for boiler tube materials, such as Alloy617, Alloy740 and and HR6W. It was reported that the effect of plastic strain on creep rupture strength is significantly different in each materials [6 11]. However, there are few reports that showed the effect of plastic strain on creep strength of Alloy263. In this paper, creep strength and microstructure change during creep deformation of Alloy 263 pre-strained up to $30 \%$ were investigated to reveal the effect of pre-strain on the creep property of Alloy 263.

\section{Experimental Procedures}

Alloy263 was prepared from solution-treated tube at 1423 
$\mathrm{K} / 2 \mathrm{~h} \mathrm{WQ}$ with outer radius of $38 \mathrm{~mm}$ and inner radius of 8.8 $\mathrm{mm}$. Chemical composition of Alloy 263 is shown in table 1 . Pre-strain was introduced by tensile test up to $30 \%$ at room temperature. Creep test specimens with a diameter of $6 \mathrm{~mm}$ and gauge length of $30 \mathrm{~mm}$ were obtained parallel to the longitudinal direction of the tube. Creep tests were conducted at temperatures of 1023 1073 K and stress range of 140 100 $\mathrm{MPa}$. In the several pre-strained specimens, creep tests were interrupted at the rupture time of non-strained sample. Microstructure observation was conducted in the parallel portion of the specimen by using optical microscope (OM), scanning electron microscope (SEM), scanning transmission electron microscope (STEM).

Area fraction of grain boundaries covered by precipitates was calculated by following equation [11].

$$
\rho=1-\Sigma \frac{l_{i}}{L}
$$

Where $l_{i}$ and $L$ are the length of grain boundaries covered by precipitates and total grain boundary length, respectively. $\rho$ was calculated from more than 5 secondary electron images (SEIs) with magnification of 2,000x. Average particle size of $\mathrm{Ni}_{3}(\mathrm{Al}, \mathrm{Ti})-\boldsymbol{\gamma}^{\prime}$ and $\mathrm{M}_{23} \mathrm{C}_{6}$ carbide inside of the grains was calculated by the diameter from TEM images taken at $20 \mathrm{kx}$ from more than 3 areas. Average particle size of grain boundary $\mathrm{M}_{23} \mathrm{C}_{6}$ carbide was calculated from back scattered electron images (BEIs) taken at $2 \mathrm{kx}$ from more than 3 areas. Samples were electron-etched using $10 \%$ oxalic-acid reagent. Orientation analysis was conducted by OIM (Orientation Imaging Microscopy) analysis at acceleration voltage of 20 $\mathrm{kV}$, work distance of 15 and step size of $0.25 \mu \mathrm{m}$.

Table 1. The chemical composition of Alloy 263 (wt.\%).

\begin{tabular}{|c|c|c|c|c|c|c|c|c|c|c|}
\hline & $\mathbf{C}$ & $\mathbf{N i}$ & $\mathrm{Cr}$ & Mo & Co & Al & $\mathbf{T i}$ & $\mathbf{N b}$ & Si & $\mathbf{F e}$ \\
\hline Alloy263 & 0.06 & Bal. & 20 & 6 & 20 & 0.4 & 2.2 & $\mathrm{R}$ & 0.1 & 0.7 \\
\hline
\end{tabular}

\section{Results}

\subsection{Initial Microstructure}

Figure 1 presents SEIs showing initial microstructures of
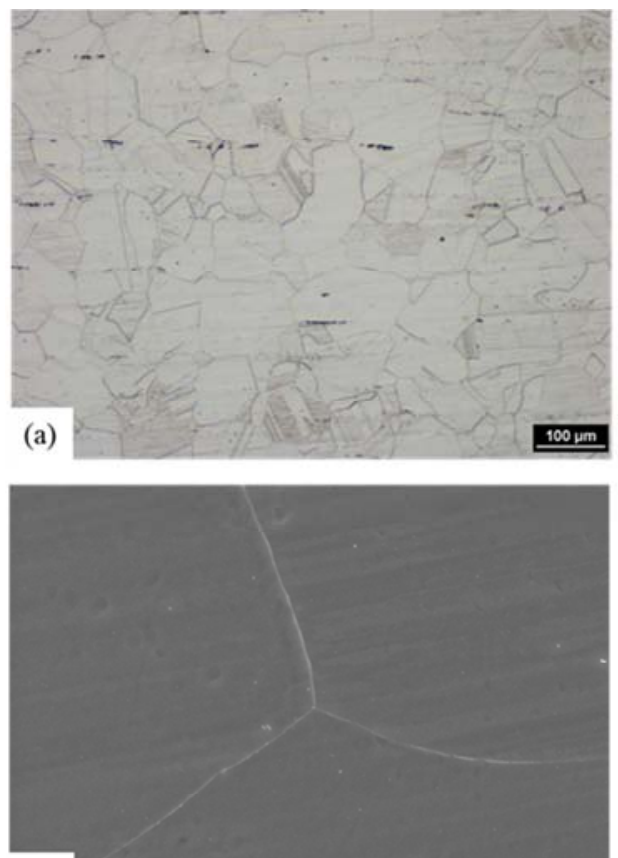

(c) non-strained and pre-strained samples that were solution treated at $1423 \mathrm{~K} / 2 \mathrm{~h}$ WQ. Each sample showed equiaxed microstructure of a single phase of $\gamma-\mathrm{Ni}$ with a mean grain size of $150 \mu \mathrm{m}$. Few precipitates existed inside of the grains and at grain boundaries in both samples.
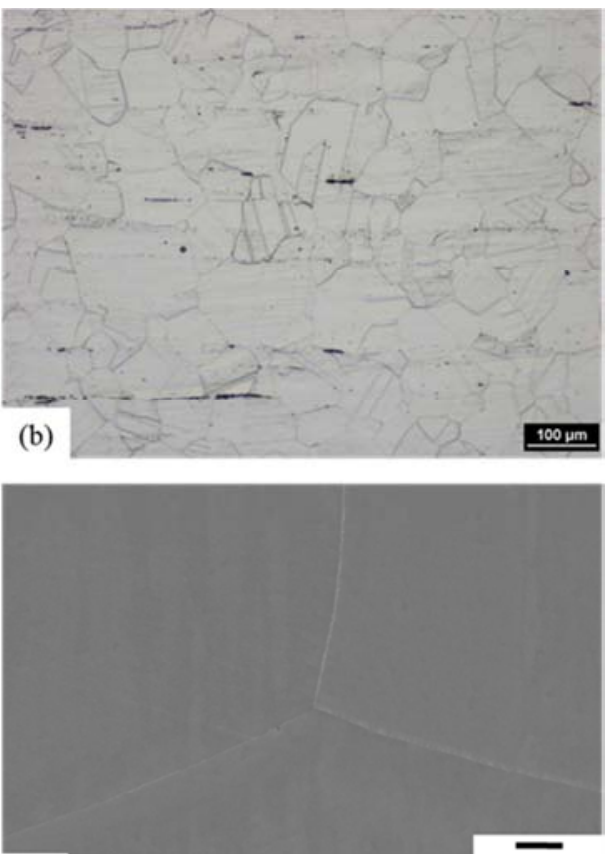

(d)

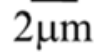

Figure 1. Alloy263 OM images and SEIs showing the initial microstructure of non-strained sample (a, c) and pre-strained sample by $30 \%$ (b, d).

\subsection{Creep Properties}

Figure 2 shows the dependence of stress on the Larson-Miller parameter $(\mathrm{C}=20)$ of non-strained and pre-strained samples at 1023, $1073 \mathrm{~K}$. Creep rupture life of pre-strained samples increased by 1.3 times at higher stress level. They showed similar behavior at 1023 K. Figure 3 shows the creep rate - time curves of the non-strained and the pre-strained samples at $1073 \mathrm{~K}$ at $140 \mathrm{MPa}$. The arrow on the creep rate-time curve represents the point of interruption in creep tests of the pre-strained sample. The point of interruption of creep in the pre-strained sample is equivalent to rupture time of non-strained sample. In the transient creep stage, the strain rate decreased rapidly in both samples since then they shifted to acceleration creep without a steady state creep. There was few 
effect of work hardening on transition creep behavior in pre-strained sample. Non-strained sample reached the minimum creep rate of $1.0 \times 10^{-5} \mathrm{~s}^{-1}$ whereas pre-strained sample reached the minimum creep rate of $7.2 \times 10^{-6} \mathrm{~s}^{-1}$ that was 1.4 times lower than non-strained sample consuming more than 5 times longer time. Figure 4 shows the creep strain-creep rate curves of non-strained and pre-strained samples at $1073 \mathrm{~K}$ at
$140 \mathrm{MPa}$. Strain at minimum creep rate of pre-strained sample was $0.2 \%$ that was larger as twice as non-strained sample. However, accumulated creep strain of pre-strained sample after the acceleration creep was quiet few. In addition, rupture strain of pre-strained sample was only $4 \%$, which was significantly lower than non-strained sample of $40 \%$.

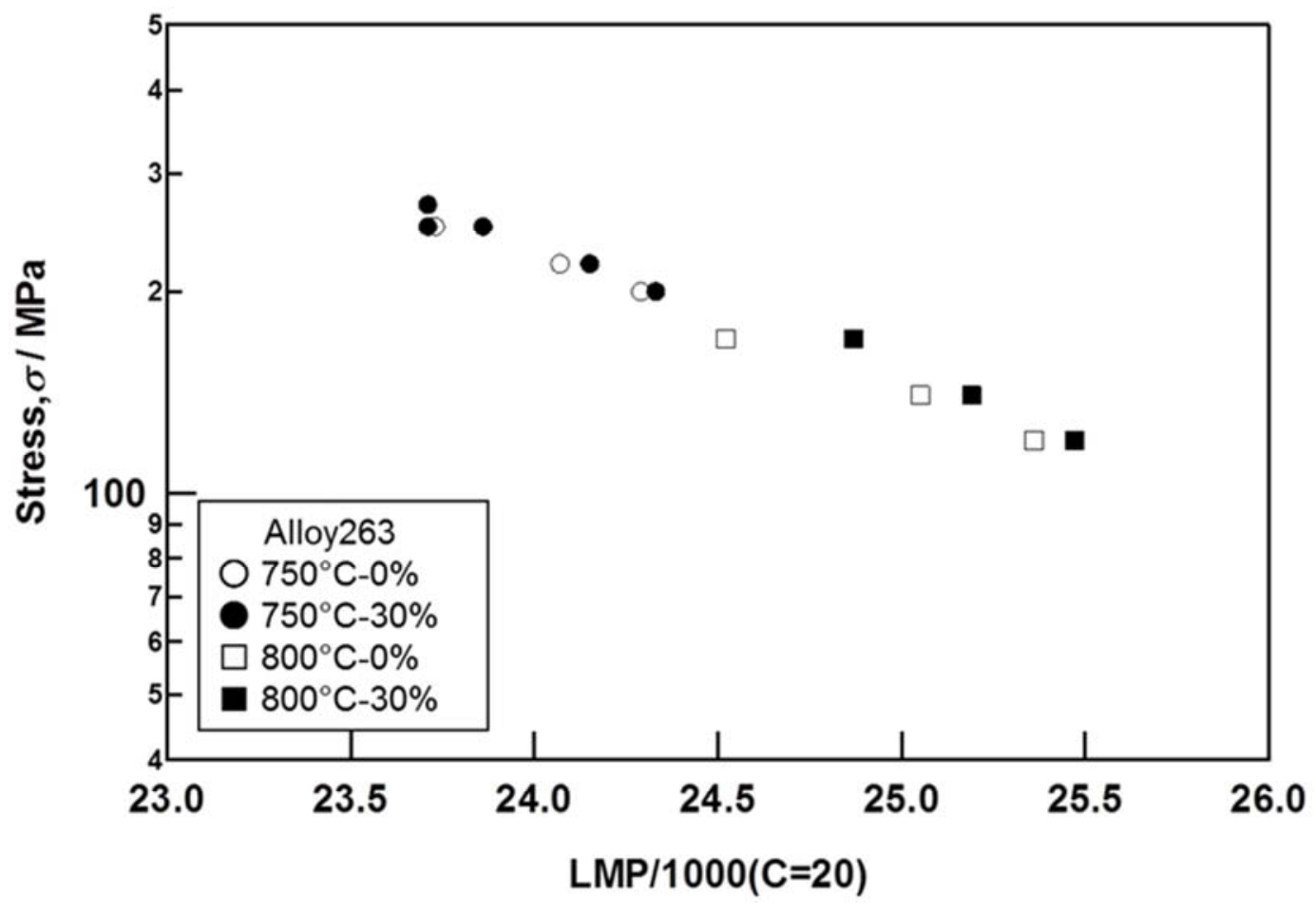

Figure 2. Creep rupture strength of non-strained and pre-strained Alloy263 at $1073 \mathrm{~K}$ and $1023 \mathrm{~K}$.

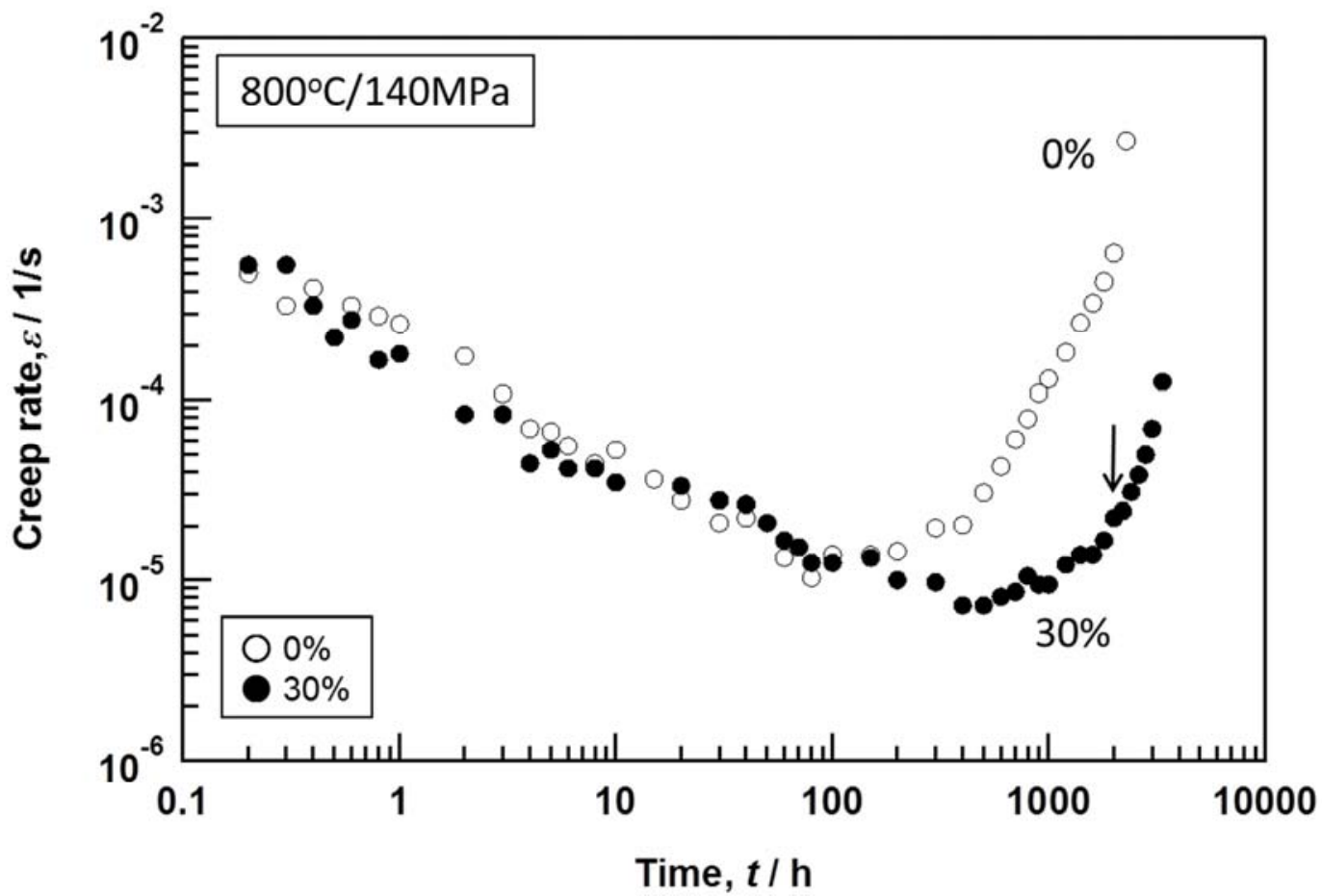

Figure 3. Creep rate-time curves of non-strained and pre-strained Alloy263 at $1073 \mathrm{~K}$ at $140 \mathrm{MPa}$. 


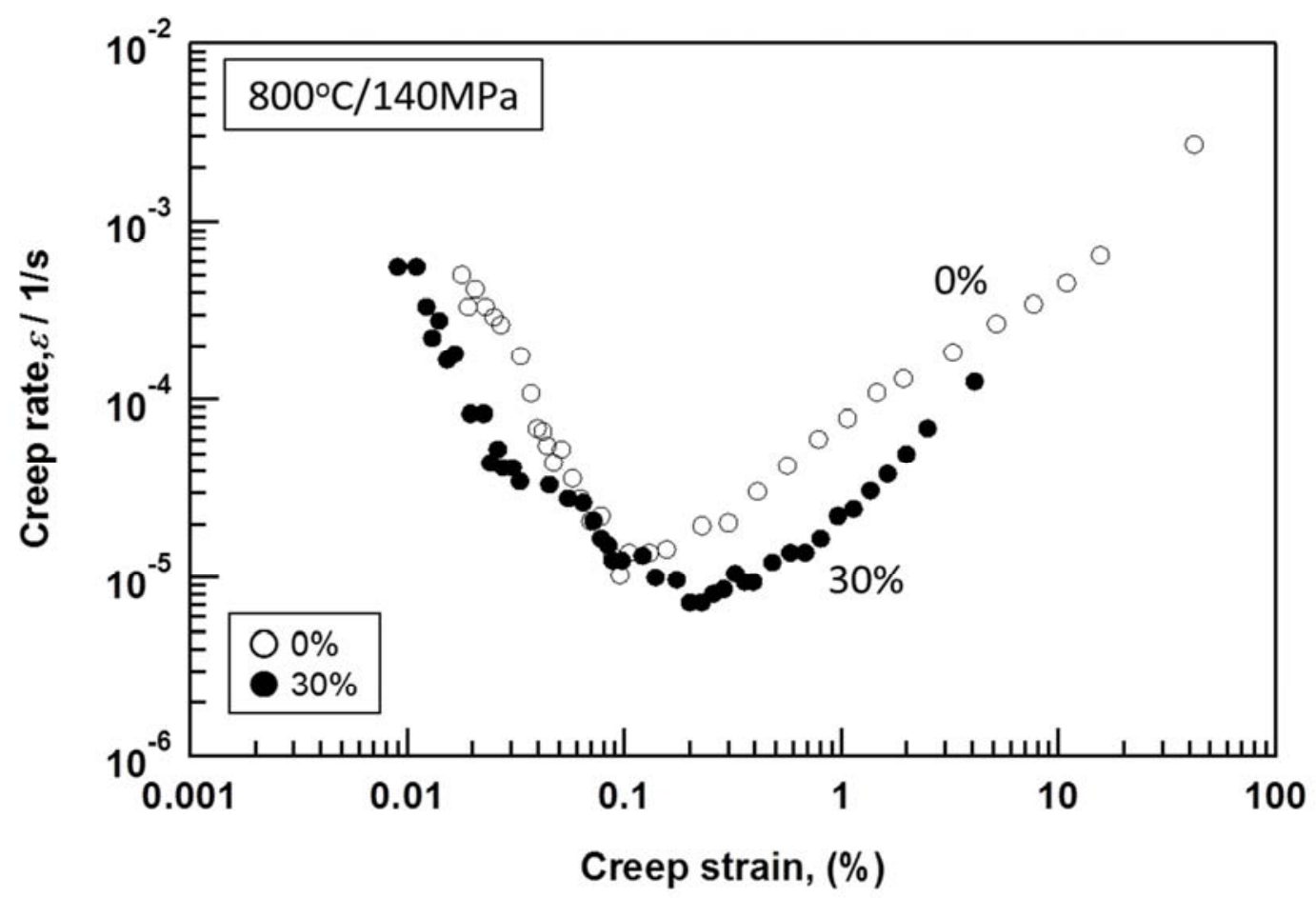

Figure 4. Creep-rate-strain curves of non-strained and pre-strained Alloy263 at $1073 \mathrm{~K}$ at $140 \mathrm{MPa}$.

\subsection{Crack Distribution in the Creep Ruptured Samples}

Figure 5 shows OM images of non-strained and pre-strained samples creep ruptured at $1073 \mathrm{~K}$ at $140 \mathrm{MPa}$ taken from near rupture area (Figure $5(\mathrm{a}, \mathrm{b}))$ and central gauge portion of the specimens (Figure $5(\mathrm{c}, \mathrm{d})$ ). In the non-strained sample, cracks
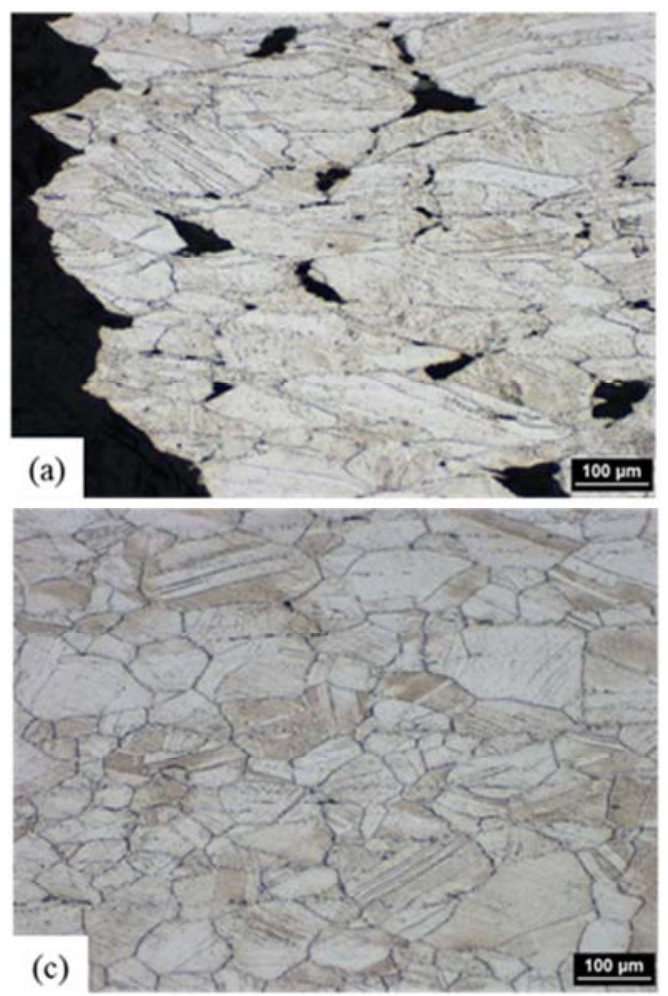

concentrated near the rupture area and few cracks were observed at the central gauge portion (Figure $5(\mathrm{a}, \mathrm{c})$ ). On the other hand, many cracks were observed at not only rupture area but also grain boundary area of the central gauge portion in the pre-strained sample (Figure $5(b, d)$ ).
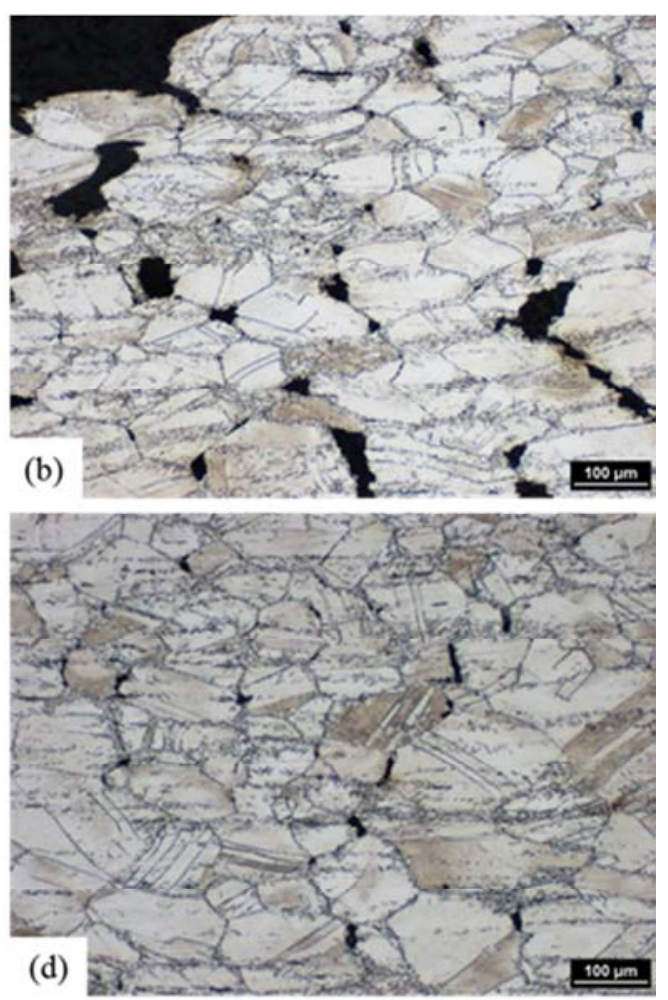

Figure 5. Microstructure of non-strained and pre-strained Alloy263 creep ruptured at $1073 \mathrm{~K}$ at $140 \mathrm{MPa}$. (a)near rupture area in non-strained sample, (b)near rupture area in pre-strained sample, (c)center portion in non-strained sample, (d)center portion in pre-strained sample. 


\subsection{Microstructure of Creep Ruptured Samples}

Figure 6 shows SEIs of non-strained and pre-strained samples creep ruptured at $1073 \mathrm{~K}$ at $140 \mathrm{MPa}$. In the grain, $\gamma$ ' particles size was about $100 \mathrm{~nm}$ in the pre-strained sample and $200 \mathrm{~nm}$ in the non-strained sample. Despite longer rupture time in pre-strained sample its $\gamma^{\prime}$ particles size was finer than
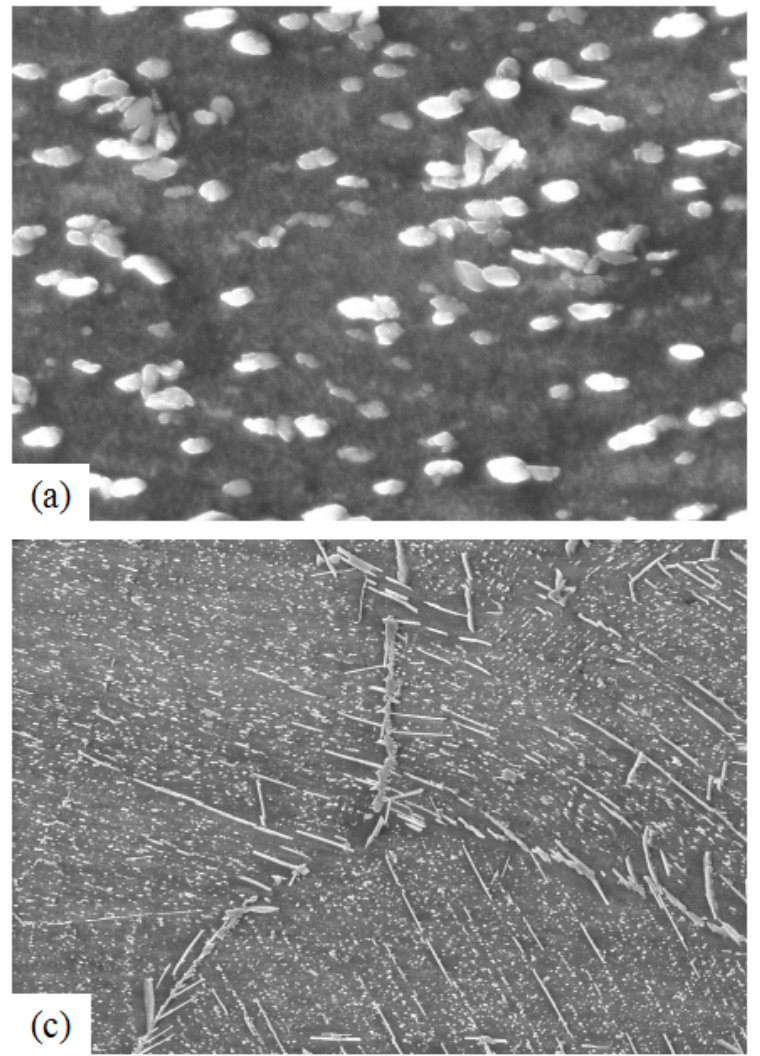

the non-strained sample (Figure 6 (c, d)). Plate-like $\eta$ phase precipitated inside of the grains and at grain boundary in both samples. At grain boundary, massive $\mathrm{M}_{23} \mathrm{C}_{6}$ carbides were observed. In addition, PFZ with width of few $\mu \mathrm{m}$ was formed around grain boundary $\eta$ phase in both samples.
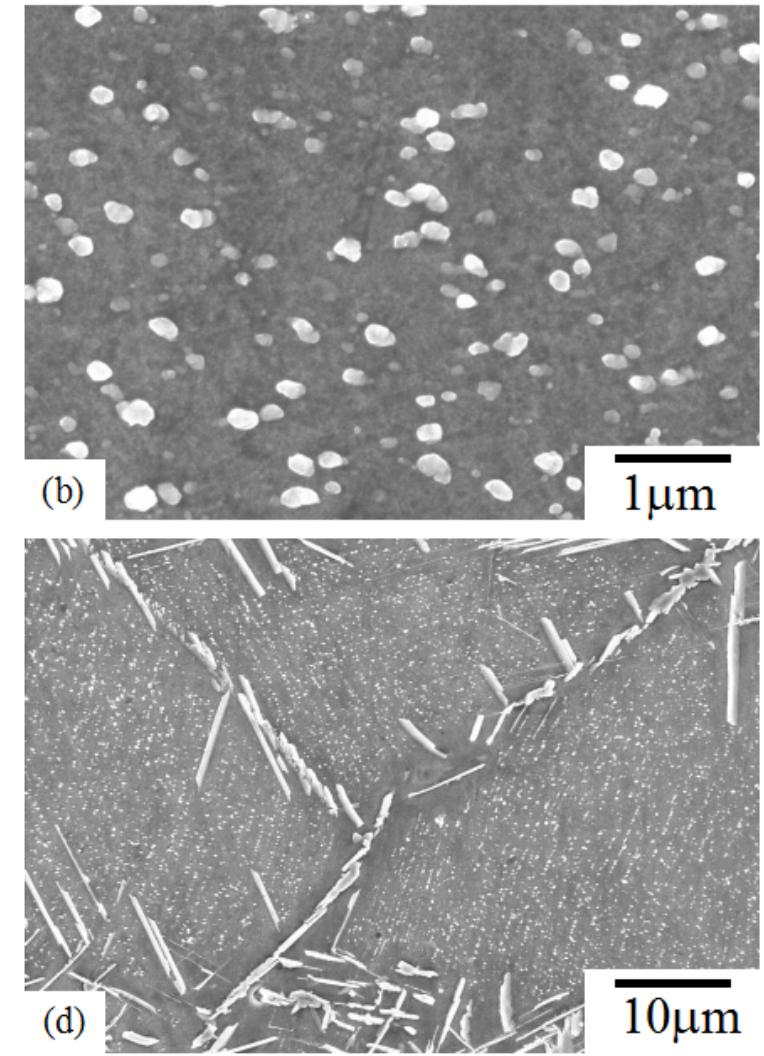

Figure 6. SEIs of creep ruptured Alloy263 at $1073 \mathrm{~K}$ at 140MPa (a)inside of the grain in non-strained sample, (b)inside of the grain in pre-strained sample, (c) grain boundary in non-strained sample, (d) grain boundary in pre-strained sample.

\section{Discussion}

\subsection{Effect of Pre-Strain on Microstructure Inside of the Grain During Creep Deformation}

It is difficult to simply compare the microstructures of pre-strained and non-strained samples shown in Figure 5 6 because creep rupture time in the pre-strained sample was 1.4 times longer than the non-strained sample. In order to compare the microstructure at the same creep time, creep test was interrupted at rupture time of the non-strained sample at 1073 $\mathrm{K}$ at $140 \mathrm{MPa}$ in the pre-strained sample indicated by arrow in Figure 3. Figure 7 shows bright field images and STEM/EDS point analysis results of $\gamma^{\prime}$ in non-strained (creep ruptured) and pre-strained (creep interrupted) samples creep deformed at the same time at $1073 \mathrm{~K}$ at $140 \mathrm{MPa}$. Average diameter of $\gamma^{\prime}$ particles in the pre-strained sample was about $150 \mathrm{~nm}$ that was much smaller than $200 \mathrm{~nm}$ in the non-strained sample. In the non-strained sample, short dislocation, its length was under $100 \mathrm{~nm}$, distributed uniformly in the grain. In the pre-strained sample, $\gamma^{\prime}$ particle distance was shorter and dislocations with about $200 \mathrm{~nm}$ length were observed. Its dislocation density was higher than the non-strained sample. STEM/EDS mapping results in these samples were shown in Figure 8. It was clear that content of Ti in $\gamma^{\prime}$ was much higher than $\mathrm{Al}$ in both samples. It explained the reason of formation of PFZ at grain boundary around $\eta$ phase in the crept samples shown in Figure 6. W. Wen-juan et. al reported that $\eta$ phase precipitation reduced volume fraction of $\gamma^{\prime}$ phase because $\eta$ phase precipitation and growth were due to diffusion of Ti that degrades creep strength of $\mathrm{Ni}-\mathrm{Co}-\mathrm{Cr}$ alloy [13]. It is also reported that intraglanuer precipitation of $\eta$ phase deteriorate mechanical property, especially strain [14].

However, in the pre-strained sample, many $\mathrm{Cr}$-rich $\mathrm{M}_{23} \mathrm{C}_{6}$ carbides were observed inside of the grains. The volume fraction of $\mathrm{M}_{23} \mathrm{C}_{6}$ carbides inside of the grains in the pre-strained sample was much higher than non-strained sample. Their particle sizes in the pre-strained sample were about $62 \mathrm{~nm}$ that was much smaller than the non-strained sample of about $167 \mathrm{~nm}$. 

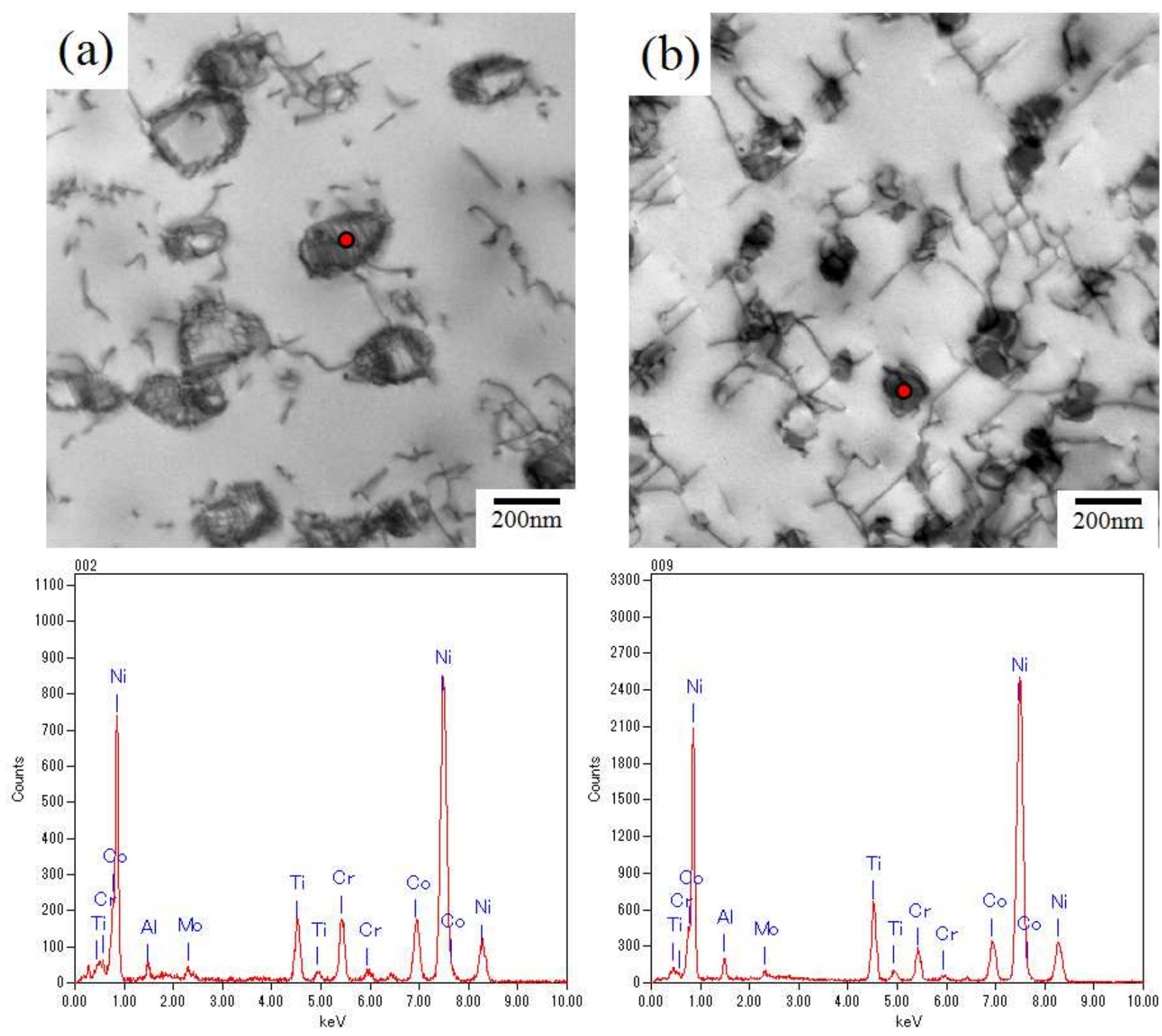

Figure 7. BFIs and STEM/EDS point analysis result of $\gamma^{\prime}$ in Alloy263 at $1073 \mathrm{~K}$ at $140 \mathrm{MPa}$ for 2,210 $\mathrm{h}$ (a) ruptured non-strained sample, (b) interrupted pre-strained sample.

Nakazawa reported that fine $\mathrm{Cr}$-rich $\mathrm{M}_{23} \mathrm{C}_{6}$ carbide precipitated on dislocation in $20 \%$ of cold worked 304 steel. Creep resistance in cold worked sample increased and creep rupture strain deteriorated due to increment in intragranuler strength by fine precipitation of intragranuler $\mathrm{M}_{23} \mathrm{C}_{6}[15]$

The effect of precipitates inside of the grain on creep deformation was discussed by Orowan stress in several works. R. C. Reed et al observed $\gamma^{\prime}$ particle and dislocations in strained U720Li, Ni-based superalloy [16]. They calculated critical resolved shear stress (CRSS) necessary to move two coupled edge dislocations in the $<110>$ direction on the $\{111\}$ plane through $\gamma^{\prime}$ particle. They revealed that when $\gamma^{\prime}$ particle size was over $50 \mathrm{~nm}$, strongly coupled dislocation pair would be activated. In the present study, CRSS necessary to glide $\gamma$ ' particle in pre-strained sample with particle size of $150 \mathrm{~nm}$ was calculated to be 1.5 times larger than non-strained sample with particle size of $200 \mathrm{~nm}$ at $973 \mathrm{~K}$ [16]. It is considered that intragranular strength in pre-strained Alloy263 will increase by fine precipitation of $\gamma^{\prime}$ and $\mathrm{M}_{23} \mathrm{C}_{6}$ carbide.

From these results, Orowan stress in Alloy263 was calculated using following equation.

$$
\tau=\frac{\mu b}{\lambda}
$$

where $\mu$ is modulus of rigidity, $b$ is a length of burgers vector, $\lambda$ is a particle distance of $\gamma^{\prime}$ phase [17]. When we took into account of only $\gamma^{\prime}$ particle, Orowan stress in the pre-strained sample was larger by 1.08 times, which was almost same to the non-strained sample. However, when we took into account of grain interior $\mathrm{M}_{23} \mathrm{C}_{6}$ particles in addition to $\gamma^{\prime}$, Orowan stress in pre-strained sample was increased by 1.7 times in the non-strained sample. It is considered that creep strength in the pre-strained samples increased due to fine precipitation of $\mathrm{M}_{23} \mathrm{C}_{6}$ carbides and $\gamma^{\prime}$ in the grain. 

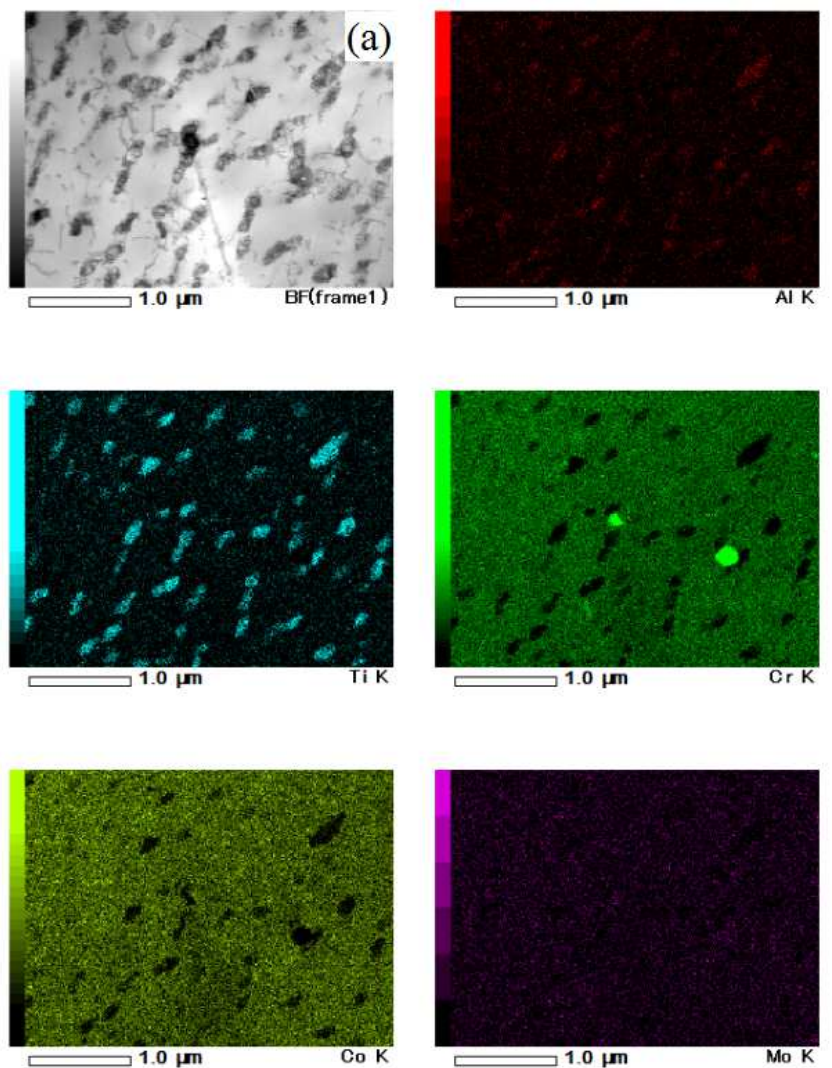
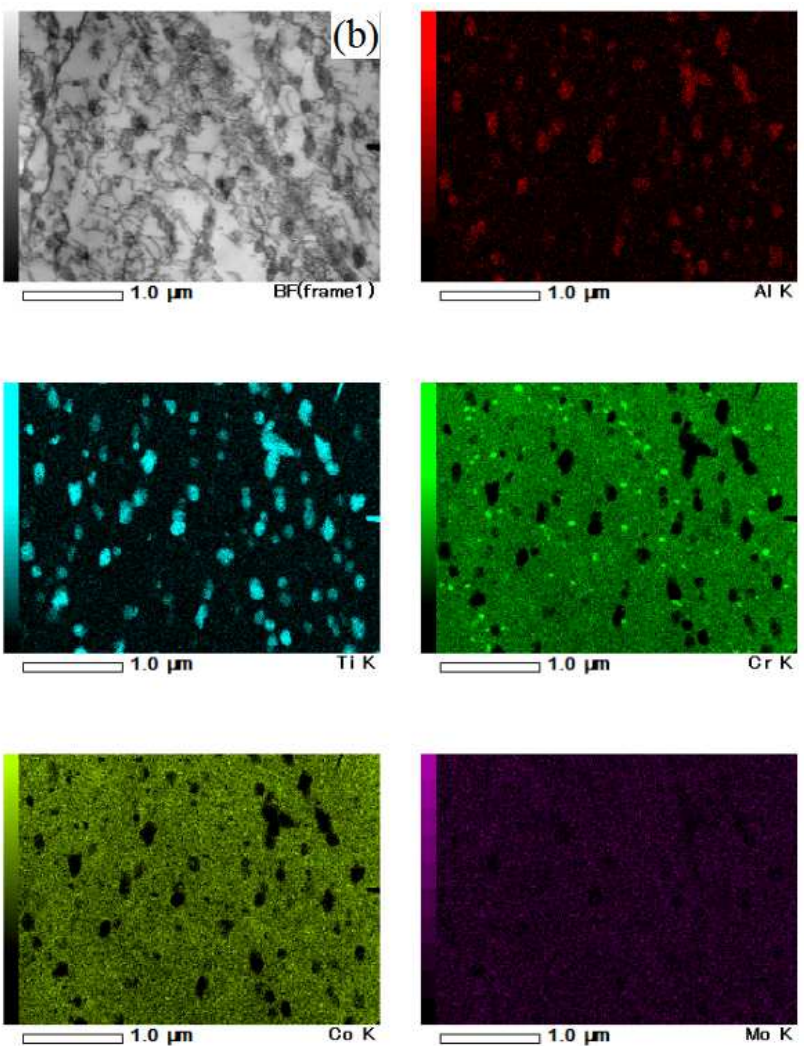

Figure 8. STEM/EDS mapping result of Alloy263 at $1073 \mathrm{~K}$ at $140 \mathrm{MPa}$ for 2,210 h (a) ruptured non-strained sample, (b) interrupted pre-strained sample.

\subsection{Effect of Pre-Strain on Grain Boundary Microstructure During Creep Deformation}

So far, several works about creep deformation mechanism for boiler tube material have been conducted. Takeyama reported that grain boundary $\alpha_{2}-\mathrm{W}$ phase suppressed grain boundary deformation during creep in Ni-20Cr-Nb-W alloy. They advocated this strength mechanism as grain boundary precipitation strengthening mechanism [18]. Matsuo et al. found out this creep strengthening mechanism observed in Nickel based alloy Nimonic $80 \mathrm{~A}$ by grain boundary $\gamma^{\prime}$ phase [19]. Recently, this mechanism was applied to boiler tube alloy for A-USC plant. It is reported that grain boundary Laves phase increase creep rupture life due to suppression of local deformation near grain boundary [20,21].

In order to consider effect of grain boundary precipitates on creep deformation near grain boundary, area fraction $\rho$ of grain boundary covered by precipitates was calcurated in both the non-strained and the pre-strained sample crept at $1073 \mathrm{~K}$ at $140 \mathrm{MPa}$. $\rho$ showed almost same value for $64 \%$ in non-strained sample and $67 \%$ in pre-strained sample respectively. It is considered that improvement of creep property by grain boundary precipitation strength was limited at present creep condition.

Figure 9 shows Kernel average misorientation (KAM) maps near grain boundary creep interrupted and ruptured at $1073 \mathrm{~K}$ at $140 \mathrm{MPa}$ in the non-strained and pre-strained samples. In the non-strained sample, a lot of small angle boundaries with under 5 degree of misorientation formed near grain boundary which represents that formation of sub-boundary was processing. On the other hand, recrystallization has been finished in the creep interrupted pre-strained sample. This results shows recrystallization has been promoted by pre-strain. Recrystallization occurs by migration of initial grain boundary which indicates discontinuous dynamic recrystallization (DDRX) was under formation [22-24]. Several micro-cracks were observed at grain boundaries where recrystallization has not occur in creep ruptured sample. These results show dynamic recrystallization was promoted by pre-strain and micro cracks formed at the end of acceleration creep near initial grain boundary where dynamic recrystallization has not occur.

Blocky $\mathrm{M}_{23} \mathrm{C}_{6}$ carbides at grain boundary in creep ruptured non-strained sample and creep interrupted pre-strained sample at $1073 \mathrm{~K}$ at $140 \mathrm{MPa}$ were shown in Figure 10.

Particle size of grain boundary carbides in non-strained sample was about $176 \mathrm{~nm}$ whereas pre-strained sample showed slightly smaller particle size of $122 \mathrm{~nm}$ than the non-strained sample.

It is considered that resistance against crack propagation at grain boundary was increased due to fine precipitation of grain boundary carbides, which explains increase of crack density in pre-strained sample shown in Figure 5. 

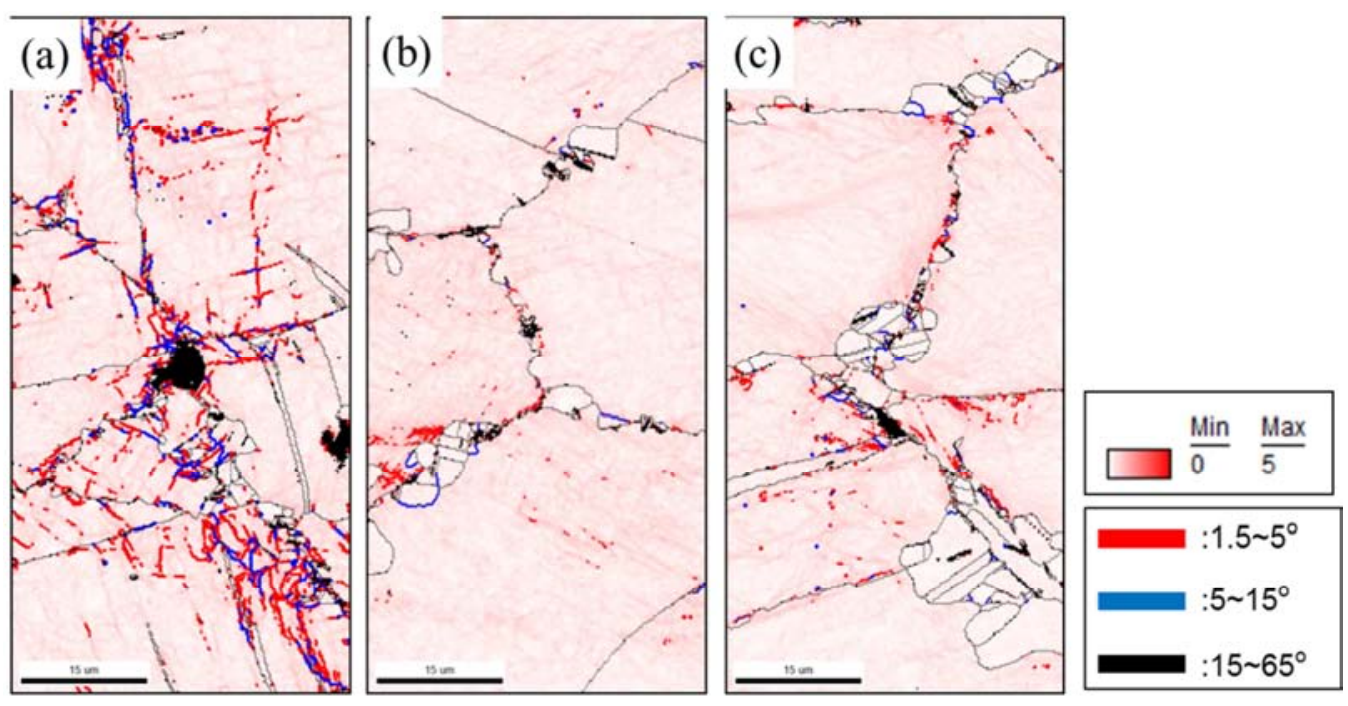

Figure 9. KAM maps of Alloy263 near grain boundary at $1073 \mathrm{~K}$ at 140MPa (a)non-strained ruptured sample, (b)pre-strained interrupted sample at rupture time of non-strained sample, (c)pre-strained ruptured sample.
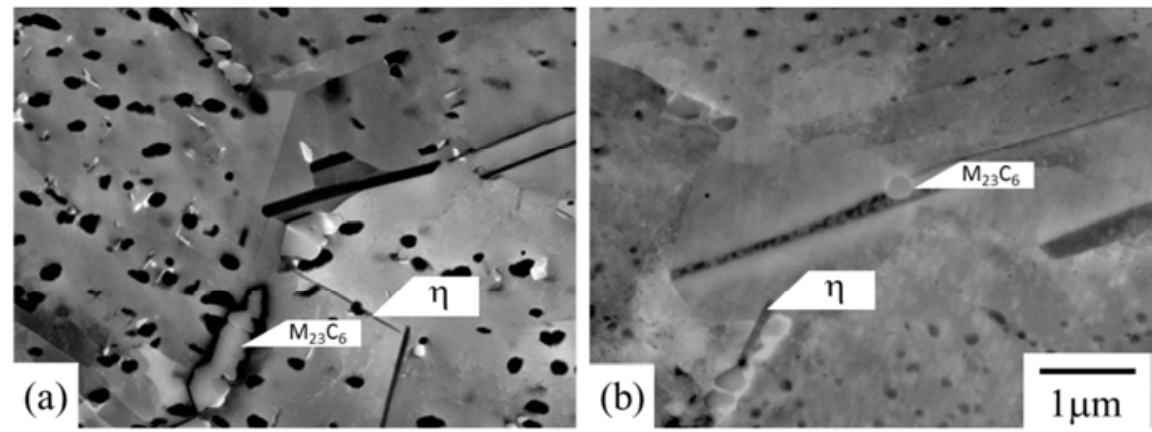

Figure 10. BEIs of Alloy263 neat grain boundary at $1073 \mathrm{~K}$ at 140MPa. (a) ruptured non-strained sample, (b) interrupted pre-strained sample.

It is reported that fine and discontinuous precipitates at grain boundaries would enhance the notch toughness of alloys at elevated temperature because grain boundary migration and grain boundary sliding were limited [13]. Mino revealed that recrystallization at grain boundary during creep in cold worked Alloy617 deteriorated creep strength and grain boundary carbides suppressed grain boundary migration [9]. In this work, fine $\mathrm{M}_{23} \mathrm{C}_{6}$ carbides at grain boundary in pre-strained sample were considered to enhance resistance against creep deformation at grain boundary during transient creep and crack propagation during acceleration creep.

Accordingly, creep deformation mechanism in pre-strained Alloy263 was investigated in this study. In the transition creep, creep rate decreased by precipitation hardening of $\gamma^{\prime}$ and $\mathrm{M}_{23} \mathrm{C}_{6}$. carbides inside of the grain. Few effect of dislocation hardening was observed on the creep resistance of pre-strained samples. Then, non-strained sample started acceleration creep earlier due to coarsening of $\gamma^{\prime}$ at minimum creep rate. On the other hand, dynamic recrystallization and formation of $\eta$ phase accompanying formation of precipitation free zone (PFZ) occured in the pre-strained sample at the same time. However, pre-strained sample kept transition creep due to the effect of fine precipitation of $\gamma^{\prime}$ and $\mathrm{M}_{23} \mathrm{C}_{6}$ carbide inside of the grain. After onset of acceleration creep in non-strained sample, dynamic recrystallization and formation of $\eta$ phase with formation of PFZ resulted in initiation of cracks at initial grain boundary where recrystallization had not finished. On the other hand, pre-strained sample showed acceleration creep due to coarsening of $\gamma^{\prime}$ phase. During acceleration creep deformation, cracks initiated at grain boundary while fine carbides at grain boundary suppressed crack propagation. On the basis of these results, increment of creep strength in pre-strained samples was due to the effect of fine precipitation of carbides and $\gamma$ inside of the grain which overcame weakening effect of dynamic recrystallization and the formation of PFZ at grain boundary.

\section{Conclusion}

In this study, the effect of pre-strain on creep strength and microstructure change during creep deformation in Alloy263 were investigated. The obtained results are as follows.

(1) Minimum creep rate time and rupture time increased by pre-strain whereas rupture strain decreased drastically by introduction of $30 \%$ pre-strain in Alloy 263 .

(2) Fine precipitation of $\gamma^{\prime}$ and $\mathrm{M}_{23} \mathrm{C}_{6}$ inside of the grain was observed in pre-strained sample. In addition, grain boundary $\mathrm{M}_{23} \mathrm{C}_{6}$ precipitated finer and by pre-strain.

(3) $\eta$ phase precipitated accompanying formation of $\mathrm{PFZ}$ at grain boundary during creep in Alloys263. However, area 
fraction of grain boundary covered by precipitates $(\rho)$ did not changed by pre-strain. Furthermore, dynamic recrystallization at grain boundary was promoted by pre-strain.

(4) Creep strength of pre-strained Alloy 263 increased due to fine precipitation of $\gamma^{\prime}$ and $\mathrm{M}_{23} \mathrm{C}_{6}$ carbide inside of the grain by pre-strain. Weakening effect of dynamic recrystallization and precipitation of $\eta$ phase during creep on creep properties of pre-strained Alloy263 have not be observed under present creep condition.

\section{References}

[1] International Energy Agency, World Energy Outlook 2009 (2009).

[2] R. Viswanathan, J. F. Henry, J. Tanzosh, G. Stanko, J. Shingledecker, B. Vitails, R. Purgert, U. S. program on materials technology for ultra-supercritical coal power plants, JMEPEG 14 (2005) 281-292.

[3] M. Fukuda, Advanced USC, The Thermal and Nuclear Power 62 (2011) 731-741 (in Japanese).

[4] K. Muroki, IHI Engineering Review Vol. 55 No. 4 (2015) 28-31 (in Japanese).

[5] S. Takano, Y. Aoki, K. Kubushiro, S. Tomiyama, H. Nakagawa, Development of 700 degree celsius class advanced ultra-supercritical boiler, IHI Engineering Review 49 (2009) 185-191 (in Japanese).

[6] K. Kubushiro, K. Nomura, T. Matsuoka, H. Nakagawa, K. Muroki, Development of boiler technology for $700^{\circ} \mathrm{C}$ A-USC plant, IHI Engineering Review 55 (2015) 81-91 (in Japanese).

[7] H. C. Yang, L. S. Wang, D. P. Wang, S. Y. Mao, X. C. Yang, X H. Lai, J. B. Yang, W. Yang, Discussion of Delivered Condition Specified in ASME CODE 2702 on INCONEL $740 \mathrm{H}$ Used for A-USC Boiler, Advances in materials technology for fossil power plants $7^{\text {th }}$ international conference, Waikoloa, Hawaii (2013) 276-280.

[8] S. Chomette, J-M Gentzbittel, B. Viguier, Creep behavior of as received, aged and cold worked INCONEL 617 at $850^{\circ} \mathrm{C}$ and $950^{\circ} \mathrm{C}$, Journal of Nuclear Materials 399 (2010) 266-274.

[9] K. Mino, A. Ohtomo, Y. Saiga, Effect of Grain Boundary Migration and Recrystallization on the Creep Strength of Inconel 617, Tetsu to Hagane Vol. 63 (1977) 2372-2380 (in Japanese).

[10] K. Kubushiro, T, Matsuoka, Y. Ohkuma, H. Nakagawa and H. Aoki, Development of welding and fabrication technologies in advanced USC boiler, Advances in materials technology for fossil power plants $7^{\text {th }}$ international conference, Waikoloa, Hawaii (2013) 1047-1058.

[11] F. Mueller, A. Scholz, C. Berger, R. U. Husemann, Influence of cold working on creep and creep rupture behavior of materials for super-heater tubes of modern high-end boilers and for built-in sheets in gas turbines, creep and fracture in high temperature components ECCC creep conference (2009) 1236-1246.

[12] N. Kanno, K. Yoshimura, N. Takata, I. Tarigan and M. Takeyama, Mechanical properties of austenitic heat-resistant Fe-20Cr-30Ni-2Nb steel at ambient temperature, Mater. Sci. Eng. A 662 (2016) 551-563

[13] W. Wen-juan, H. Guang-wei, Influence of Aging on Treatment on Precipitation Behavior of $\eta$ Phase in Ni-Co-Cr Alloy, D. Bo, Journal of Iron and Steel Research, INTERNATIONAL 17 (2010) 64-69.

[14] Danflou H. L, Marty M, Walder A. Formations of Serrated Grain Boundaries and Their Effect on the Mechanical Properties in a P/M Nickel Base Superalloy, Superalloys 1992 (1992) 63-72.

[15] T. Nakazawa, H. Annpo, The Effect of Some Factors on the Creep Behavior of Type 304 Stainless Steel, Tetsu to Hagane Vol. 63 (1977) 82-91 (in Japanese).

[16] M. P. Jackson, R. C. Reed, Heat treatment of U720Li: the effect of microstructure of properties, Materials Science and Engineering A 259(1999) 85-97.

[17] M. Kato, Introduction to the theory of dislocations (1999).

[18] M. Takeyama, K. Kawasaki, T. Matsuo, R. Tanaka, Effect of Grain Boundary Precipitates on High Temperature Creep Properties of Ni-20Cr-Nb-W Alloys, Tetsu to Hagane Vol. 72 (1986) 1605-1612 (in Japanese).

[19] A. M. Elbatahgy, T. Matsuo, K. Kikuchi, Grain Boundary Precipitation Strengthening due to g' Phase in High Temperature Creep of a Ni-base Superalloy, Tetsu to Hagane Vol. 76 (1990) 765-774 (in Japanese).

[20] K. Kurata, N. Takata, T. Matsuo, M. Takeyama, Effect of Grain Boundary Laves Phase on Creep Resistance of Fe-20Cr-30Ni-2Nb Austenitic Heat Resistant Steels, Report of the 123 rd Committee on Heat-Resisting Materials and Alloys, Japan Society for the Promotion of Science, Vol. 49 (2008) 379-389 (in Japanese).

[21] T. Imanuel, T. Takata, M. Takeyama, Influence of Grain Boundary $\mathrm{Fe}_{2} \mathrm{Nb}$ Laves Phase in Creep Properties of Fe-20Cr-30Ni-2Nb Austenitic Heat Resistant Steels at 973K, Report of the 123 rd Committee on Heat-Resisting Materials and Alloys, Japan Society for the Promotion of Science, Vol. 52 (2011) 63-72.

[22] N. Tsuji, Formation Mechanisms of Ultrafine Grained Structures in Severe Plastic Deformation of Metallic Materials, Tetsu-to-Hagane Vol. 94 (2008) 8-15 (in Japanese).

[23] A. Belyakov, H. Miura, T. Sakai, Dynamic recrystallization under warm deformation of a 304 type austenitic stainless steel, Materials Science and Engineering A255 (1998) 139-147.

[24] N. Dudova, A. Belyakov, T. Sakai, R. Kaibyshev, Dynamic recrystallization mechanisms operating in a $\mathrm{Ni}-20 \% \mathrm{Cr}$ alloy under hot-to-warm working, Acta Materialia 58 (2010) 3624-3632. 